\title{
Risk-Adjusted Poverty in Argentina: Measurement and Determinants
}

\author{
by \\ Guillermo Cruces \\ London School of Economics and Politcal Science \\ and \\ Quentin Wodon \\ The World Bank
}

Discussion Paper

No. DARP 72

September 2003
Distributional Analysis Research Programme

The Toyota Centre Suntory and Toyota International Centres for Economics and Related Disciplines London School of Economics Houghton Street London WC2A 2AE

Acknowledgements: We are very grateful to Frank Cowell for comments provided on previous drafts of this paper. We are also grateful for comments received at seminar presentations at a 2002 World Bank-IFPRI conference on Vulnerability and Risk, at the 2002 Argentina meeting of the LACEA/IADB/WB network on Inequality and Poverty, and finally at the 2003 WIDER Conference on Inequality, Poverty and Human Well-Being. The usual disclaimer applies. This paper was prepared as a background study for the poverty assessment for Argentina prepared by Norman Hicks at the World Bank. The views expressed here are those of the authors and need not reflect those of the World Bank. 


\begin{abstract}
Relying on a Constant Relative Risk Aversion utility function, we use panel data for Argentina to compute risk-adjusted income and poverty measures and to analyze their determinants. Taking risk into account increases poverty. The regression analysis suggests that many household characteristics are correlated not only with the average income of the household over time, but also with income variability.
\end{abstract}

Keywords: Risk, Poverty, Argentina

JEL Nos.: D81, I32, D63

(C) Guillermo Cruces and Quentin Wodon. All rights reserved. Short sections of text, not to exceed two paragraphs, may be quoted without explicit permission provided that full credit, including (C) notice, is given to the source.

Contact addresses:

Guillermo Cruces, Department of Economics and STICERD, London School of Economics and Political Science, Houghton Street, London WC2A 2AE, UK. Email: g.a.cruces@1se.ac.uk

Quentin Wodon, The World Bank, 1818 H Street NW, Washington, DC 20433, USA. Email: gwodon@worldbank.org 


\section{Distributional Analysis Research Programme}

The Distributional Analysis Research Programme was established in 1993 with funding from the Economic and Social Research Council. It is located within the Suntory and Toyota International Centres for Economics and Related Disciplines (STICERD) at the London School of Economics and Political Science. The programme is directed by Frank Cowell. The Discussion Paper series is available free of charge and most papers are downloadable from the website. To subscribe to the DARP paper series, or for further information on the work of the Programme, please contact our Research Secretary, Sue Coles on:

Telephone:

Fax:

Email:

Website:
$\mathrm{UK}+2079556678$

$\mathrm{UK}+2079556951$

s.coles@1se.ac.uk

http://sticerd.lse.ac.uk/DARP 


\section{Introduction}

There is ample evidence that poor (and not-so-poor) households are vulnerable to shocks. As suggested by Blundell and Preston (1998) for Britain, if insurance markets were complete, households would be able to offset the impact of shocks on consumption. But in developing countries, safety nets and credit markets tend not to be well developed. This is why the latest World Development Report on poverty produced by the World Bank (2001) insists on the need to provide "security" to the poor in addition to opportunities and empowerment. One of the first studies in this area by Ravallion (1988) analysed how a risk that is commonly shared among households may affect expected poverty. Jalan and Ravallion (1999) examined how well household consumption is insured against income variability in rural China. They found that consumption is never fully insured and that poorer households are less well insured than other households. A series of papers published in a special issue of the Journal of Development Studies by Baulch and Hoddinott (2000), Baulch and McCullogh (2000), Dercon and Krishnan (2000), Jalan and Ravallion (2000), Gunning, Hoddinott, Kinsey and Owens (2000), and Scott (2000) provided additional evidence on the relationships between risk, vulnerability, and poverty. ${ }^{1}$

In much of the above work, and more generally in much of the literature, the relationships between risk, vulnerability, and poverty have been analyzed from the point of view of the impact of shocks (whether covariant or idiosyncratic) on movements in and out of poverty, with the concept of vulnerability somewhat vaguely defined as the risk of falling into poverty. ${ }^{2}$ In this paper, we do not rely on the concept of vulnerability nor on the analysis of movements in and out of poverty. Instead, we directly incorporate risk into the measurement of income, and thereby poverty. Our approach is based

${ }^{1}$ Additional works were recently presented at a workshop on this topic at the International Food Policy Research Institute, among others by Chaudhuri, Jalan and Suryahadi (2002), Christiaensen and Subbarao (2001), Dabalen and Popuart (2002), Ligon and Schechter (2002), Mansuri and Healy (2002), Skoufias and Quisumbing (2002), as well as the present paper.

${ }^{2}$ There are exceptions to this, for example Ligon and Schechter (2002). 
on the standard concepts of risk aversion and certainty-equivalent income or consumption. ${ }^{3}$ Specifically, using a Constant Relative Risk Aversion utility function, we use panel data to compute a risk-adjusted income measure at the household level. This is then used to estimate risk-adjusted poverty measures and to assess the determinants of risk-adjusted income and poverty. This methodology was first applied to risk-adjusted measures of inequality by Makdissi and Wodon (2003), and extended to comparisons of long term relative deprivation between groups by Cruces, Makdissi and Wodon (2002).

We illustrate the framework with panel data for urban households living in the Greater Buenos Aires Area in Argentina ${ }^{4}$ for the period 1995-2002. The use of Argentine data is especially appropriate given the repeated shocks that have affected the country. After a "lost decade" in the eighties that ended up in a process of hyperinflation, Argentina adopted a hard peg of the local currency to the US dollar in 1991 (the so called Convertibility Plan). The period 1991-1994 was relatively stable, but the currency board implied that the economy remained vulnerable to external shocks. In 1994-1995, the country was hit by contagion of the "Tequila effect" following Mexico's devaluation. After a period of recovery from 1996 to 1998, the economy suffered again when Brazil, Argentina's main trading partner, devalued its currency in January 1999. This episode marked the beginning of a three year recession that ended in a major crisis. At the end of 2001, the country's economy collapsed in a financial meltdown accompanied by a banking and currency crisis. Argentina's peso lost nearly 70 percent of its value against the US dollar from January to August 2002. Inflation increased rapidly, real wages fell

\footnotetext{
${ }^{3}$ It would be better to use consumption data for the empirical work, because this would enable us to better factor in ex post some of the smoothing strategies used by households to offset risk. Unfortunately, information on consumption is not available in a panel setting in Argentina. Therefore we use income data. This probably implies that our estimates for the impact of risk on poverty represent an upper bound, since consumption is typically less volatile than income. On the other hand, our data already factor in some of the behavioral responses of households to deal with risk - for example, some households may increase their labor force participation to offset income losses, and this will show up in the variable used to measure income over time.

${ }^{4}$ For previous work on poverty and risk in Argentina at the World Bank, see World Bank (2000, 2001b).
} 
and poverty soared to levels previously unseen. According to estimates published by Argentina's National Statistical Institute, the Instituto Nacional de Estadisticas y Censos (INDEC hereafter), from October 2001 to May 2002, the share of the population in poverty increased from 35.4 percent to 49.7 percent in the Greater Buenos Aires area, and from 38.3 to 53.0 percent for the total urban population (INDEC, 2002).

The impact of these repeated shocks is well captured in our empirical work. The results suggest that risk-adjusted poverty measures are higher than standard cross-sectional measures for reasonable values of the risk aversion parameter. Furthermore, the impact of a number of household characteristics on risk-adjusted measures differs from their impact on standard measures, which implies that these characteristics are positively or negatively correlated with risk apart from being correlated with the average level of income of households. We find that households with elderly members are less subject to risk, while households with inactive or unemployed workers suffer more from risk. Being a recent migrant increases risk even though it does not affect average income, while a better education reduces risk as well as increasing income.

The rest of the paper is organized as follows. Section 2 presents the conceptual framework for the estimation of risk-adjusted measures of income and poverty, and for the analysis of their determinants. Section 3 presents our empirical results using data from Argentina. A brief conclusion follows.

\section{Methodology}

\subsection{Risk adjusted measures of income and poverty}

Our risk-adjusted measures of poverty are based in the concept of riskadjusted income, derived from the notion of certainty-equivalent income from the risk literature.

Following Makdissi and Wodon (2003), we assume that there are $T$ possible states of nature. A household $i$ is exposed to income fluctuations over these states. The certainty-equivalent income of the household, $y_{i}$, is the 
amount of income that, if received with certainty in each possible state, would provide the same level of utility as the incomes over different states $\left(x_{i t}\right)$. Thus $y_{i}$ can be defined within a social welfare context with respect to some function $u($.$) which represents the social judgement on the welfare$ value of the random variable $x$ (Makdissi and Wodon, 2003):

$$
u\left(y_{i}\right)=\frac{1}{T} \sum_{t=1}^{T} u\left(x_{i t}\right) .
$$

The function $u($.$) is assumed to be continuous with positive first derivative$ (non satiation) and negative second derivative (risk aversion). The Constant Relative Risk Aversion (CRRA) function, widely used in the risk literature, has such properties:

$$
u(x)=\left\{\begin{array}{cc}
\frac{x^{1-\rho}}{1-\rho} & \text { if } \rho \neq 1 \\
\log x & \text { if } \rho=1
\end{array} .\right.
$$

We denote by $\rho$ the constant Arrow-Pratt relative risk aversion coefficient. A common practice in the risk literature is the use of a Taylor approximation of the certainty equivalent, defined as

$$
y_{i}^{T}(\rho)=\bar{x}_{i}-\frac{1}{2} R_{A}(\rho) \sigma_{x_{i}}^{2},
$$

where $\bar{x}_{i}$ is the mean household income over the whole period under consideration, $\sigma_{x_{i}}^{2}$ is the variance of the income of household $i$ and $R_{A}(\rho)$ is the Arrow-Pratt measure of absolute risk aversion equal to $\frac{\rho}{\overline{x_{i}}}$ for the CRRA utility function. The problem with this Taylor approximation is that it is only valid for small levels of risks, and thus likely to produce biased results for high values of $\rho$. In this paper, we use instead the "exact" measure of risk-adjusted income implied by (1) and (2), which is equal to

$$
y_{i}=\left\{\begin{array}{cc}
{\left[\frac{1}{T} \sum_{t=1}^{T} x_{i t}^{1-\rho}\right]^{\frac{1}{1-\rho}}} & \text { if } \rho \neq 1 \\
y_{i}=\prod_{t=1}^{T} x_{i t}^{1 / T} & \text { if } \rho=1
\end{array} .\right.
$$

Using (4), it is relatively straightforward to estimate risk-adjusted poverty measures based on household's income fluctuations. Since in practice we do 
not know the possible states of the world, we assume that income observations in different periods of time are drawn from the distribution given in the panel. At any given time, the poverty status of a household is defined with respect to a poverty line $z_{t}$ (which may be absolute or relative), such that households with incomes lower than $z_{t}$ are considered poor. Here, instead of focusing on the static condition $x_{i t}<z_{t}$, we use the household's risk-adjusted measure of income given by equation (4) for the $T$ periods. Note that because we have different poverty lines over time, we need to normalize (i.e., divide) the income of each household at time $\mathrm{t}$ by $z_{t}$, so that a household is considered poor if $y_{i}<1$. Note also that we need to take into account the composition of the household in defining what are its basic needs and whether it is poor or not.

Taking all of the above into consideration, we define $x_{i t}$ as follows

$$
x_{i t}=\frac{\widetilde{x}_{i t}}{z_{t}}
$$

where $\widetilde{x}_{i}$ is some form of equivalised monetary income for the household. Following standard practice in Argentina, our measure $\widetilde{x}_{i}$ of household $i$ 's equivalised income is the sum of the monetary income $\psi$ of each of the $k_{i}$ members $\left(j=1, \ldots, k_{i}\right)$ of the household, divided by the sum of each member's equivalent adult weights ${ }^{5} q_{j}$ :

$$
\widetilde{x}_{i}=\frac{\sum_{j=1}^{k} \psi_{j}}{\sum_{j=1}^{k} q_{j}} .
$$

The vector of certainty-equivalent incomes $y=\left(y_{1}, y_{2}, \ldots, y_{n}\right)$, where $n$ is the number of households, is obtained from using the $x_{i t}$ defined by (5) into (4); it is then used to compute a set of risk-adjusted measures of poverty.

${ }^{5}$ We adopt the same equivalent adult scale as INDEC, the Argentine statistical agency, to ensure comparability with other studies. The weights are obtained from a normative calory intake basket of goods. Male adults are represented by a weight of 1 , with different values according to gender and age groups. Morales (1998) provides a detailed account on the obtention of these parameters. 
We will focus here on the usual additive poverty indices of the FGT (Foster, Greer and Thorbecke, 1984) class. Since we have normalized all incomes by the poverty lines (so that a value of one for the normalized income corresponds exactly to the poverty line), the FGT measures are defined as

$$
F G T(y, \alpha)=\frac{1}{n} \sum_{y_{i} \leq 1}^{n}\left(\frac{1-y_{i}}{1}\right)^{\alpha},
$$

where $\alpha$ may be interpreted as a parameter of aversion to poverty. With $\alpha=0$, we obtain the poverty headcount. With $\alpha=1$ and $\alpha=2$, we obtain the poverty gap and the squared poverty gap respectively. These risk-adjusted poverty measures can then be compared to those obtained with the mean income over time for each household, namely

$$
F G T(\bar{x}, \alpha)=\frac{1}{n} \sum_{\overline{x_{i}} \leq 1}^{n}\left(\frac{1-\overline{x_{i}}}{1}\right)^{\alpha},
$$

Note that under standard poverty measurement procedures, a household with equivalised income just above the poverty line during the $T$ periods would not be considered poor. However, the impact of risk aversion could well make such a household poor according to our methodology if there is some variation in income over time. Note also that a potential problem arising from the use of panel data is that a steady growth over time in incomes may be interpreted as risk because it will lead to variability in income. In our application however, this is not much of an issue since the period of time for which we have panel data on each household is relatively short (1.5 years), so that growth effects should be small (for an analysis based on data for longer periods of time using relative poverty measures to correct for the impact of growth, see Cruces et al., 2002.)

\subsection{Determinants of risk-adjusted poverty}

Apart from estimating risk-adjusted measures of poverty, we also look at the determinants of risk-adjusted poverty. Typically, in a standard context, an analyst would estimate the probability of a household of being poor using a 
regression of the determinants of the logarithm of adult equivalent income, which avoids specification problems occurring with probits and logits. In this case, we do the same, but using also the logarithm of the risk-adjusted adult equivalent income as a dependent variable. More precisely, we estimate the determinants or correlates of standard income and risk-adjusted income jointly by using seemingly unrelated regression techniques (SUR), for reasons given below. Denoting by $X_{i}$ the vector of independent variables for household $i$, and again by $\overline{x_{i}}$ the mean income of the household (without adjustment for risk, i.e. with $\rho=0$ ), we estimate the following system

$$
\left\{\begin{array}{ccc}
\log \overline{x_{i}}= & \alpha+X_{i} \beta+\varepsilon_{i} \\
\log y_{i}= & \alpha^{R A}+X_{i} \beta^{R A}+\varepsilon_{i}^{R A}
\end{array} .\right.
$$

From these regressions, it is straightforward to compute the probability of being poor using either the standard or the risk-adjusted measures of adult equivalent income (e.g., Ravallion and Wodon, 1999). Denoting by $\sigma$ and $\sigma^{R A}$ the standard deviations of the errors in the mean and risk-adjusted income regressions, and by $\Phi$ the cumulative density of the standard normal distribution, the probability of being poor is given by

$$
\begin{array}{ccc}
\operatorname{Pr}\left[\log \overline{x_{i}}<0 \mid X_{i}\right]= & \Phi\left[-\left(\alpha+X_{i} \beta\right) / \sigma\right] \\
\operatorname{Pr}\left[\log y_{i}<0 \mid X_{i}\right]= & \Phi\left[-\left(\alpha^{R A}+X_{i} \beta^{R A}\right) / \sigma^{R A}\right] .
\end{array}
$$

Since we have the same set of independent variables, using SUR to estimate (9) does not change any of the coefficient estimates versus separate regressions, but it enables us to test for statistically significant differences in the determinants of both measures of income. The difference in parameter estimates between the two regressions, $\beta^{R A}-\beta$, is analogous to the estimation of a third regression for the determinants of what we might call our measure of risk:

$$
\log \overline{x_{i}}-\log y_{i}=\alpha^{R P}+X_{i} \beta^{R P}+\varepsilon_{i}^{R P} .
$$

The difference between $\overline{x_{i}}$ (mean income) and $y_{i}$ (the certainty equivalent) is the risk premium (hence the RP superscript): a higher risk premium implies a lower level of utility, since the household would be willing to give up a higher amount of income to stabilise it. In this third regression, we have $\alpha^{R P}=$ 
$\alpha-\alpha^{R A}$ and $\beta^{R P}=\beta-\beta^{R A}$. Testing for differences in the coefficient estimates in the SUR would be equivalent to testing for the statistical significance of the parameter estimates in this third "risk premium" regression, with the caveat that it would not be likely to have a normally distributed error term. In this case it is better to estimate the first two regressions and test for differences in coefficients.

A positive and statistically significant value of $\beta-\beta^{R A}$ implies that the related independent variable contributes to an increase in the risk premium, and thereby a decrease in risk-adjusted income. Independent variables for which there is a positive and statistically significant value of $\beta-\beta^{R A}$ are in fact reducing risk, and thus increasing risk-adjusted income. This approach thus provides a straightforward interpretation of the impact of various variables on risk-adjusted income and poverty, with a simple decomposition into the impact on mean income, and the impact on risk.

\section{Application to Argentina}

\subsection{Data and descriptive results}

We apply the above framework to an analysis of poverty in Argentina using the Argentine Permanent Household Survey ("Encuesta Permanente de Hogares"-EPH). The survey is collected in urban areas every year by the Instituto Nacional de Estadisticas y Censos (INDEC) in May and October. We exploit the structure of the survey, which is a rotating panel where 25 percent of the sample is replaced in each round. It is possible to observe households for four rounds (i.e., $T=4$ ), which corresponds to a total period of 1.5 year. We restrict our sample to households belonging to the Greater Buenos Aires area (GBA), which represents around 60 percent of the total population of the country and 70 percent of the urban population (and thereby of our survey sample). We use the fifteen rounds corresponding to the period May 1995-May 2002.

In order to minimize the loss of potentially important observations, the cases with reported zero incomes that were considered valid by INDEC were 
assigned a symbolic value of 1 percent of the poverty line in our analysis. This correction is necessary for computational reasons, since $y_{i}$ is not defined for $x_{i t}=0$ for $\rho>1$ (Equation 4) and we want to count on the same data for all values of the risk-aversion parameter. The poverty measures presented below are virtually unaffected by this procedure since we focus on the headcount index of poverty. Of almost 5500 households in the final sample, only two reported zero incomes in all four rounds.

Given the structure of the rotating panel, the fifteen rounds for the surveys between May 1995 and May 2002 contain data for twelve cohorts with four consecutive observations, with an average of 453 households and 1812 observations per cohort - Table 1 presents the number of observations and Table 2 depicts our distinction between rounds and cohorts. In comparison with the cross-sectional use of the data, there is a loss of observations when using the panel structure. This loss is due not only to attrition (non-response in subsequent rounds), but also to the criteria imposed by INDEC to consider a household's income observation as valid only if the income of every member of the household is reported. While the loss of observations is substantial (48 percent of the households are lost), it does not seem to affect the results in an important qualitative way. This is shown in Figure 1 which illustrates the effects of the attrition in the panel. While nominal incomes are lower in the panel (by 4.5 percent on average) versus the cross-sectional mean, the trends in income are very similar between the cross section and panel data sets. Regarding the headcounts of poverty, the average difference between the cross-sectional and panel measures is only 0.14 percentage points. ${ }^{6}$ Thus, although our final sample has lower incomes than the full sample, we do not expect the potential increase in poverty to invalidate our main results.

Figure 2 presents the estimates of the adult equivalent income based on a cross-sectional use of the panel sample (thick broken line), as well as the risk-adjusted poverty estimates for $\rho=0,1,2$, and 4 (Cf. equation 4 ). The latter is calculated for each of the twelve cohorts for which we have four

\footnotetext{
${ }^{6}$ Note that the apparently large difference for the last wave is a consequence of the lower number of observations for the first and last waves (see Table 2).
} 
observations.

In terms of broad trends, after the "Tequila" crisis of 1995, the country recovered from 1996 to 1998. Since then, however, the losses in income have been very large, first due to the prolonged recession of 1999-2001, and thereafter due to the devaluation and subsequent crisis of 2002. Cruces and Wodon (2003a, 2003b) present a more detailed description of poverty trends and dynamics, and an analysis of transient and chronic poverty over this period, respectively.

As expected, the cross-sectional mean and the panel mean (which corresponds to $y_{i}$ with $\rho=0$ ) are very similar, but we can still observe the smoothing effect introduced by the averaging across the cohort, notably in the last observation corresponding to the 2001/2002 crisis, where there was an enourmous fall in cross sectional income which affected the cohort mean only partially.

Regarding the risk-adjusted measures, higher values of $\rho$ lead to reductions in the mean risk-adjusted income, which can be substantial as observed in the graph: going from values of $\rho=0$ to $\rho=4$ reduces log-income by more than $15 \%$.

Figures 3 and 4 provide similar information for the headcount of poverty, i.e. the share of the population with adult equivalent income below the poverty line, corresponding to the FGT measure with $\alpha=0$ (Equation 7 ). The distinction between the two Figures is that one is obtained by considering rounds, while the other is obtained by considering cohorts. When the analysis is done by round, we use all households which appear in one survey, say May 1998. In order to have four observations for all households in that round, we must go forward in time for some, and backward in time for others (or both). When the analysis is done by cohort, we use all households with observations starting at a given point in time, and we follow them through time. Table 2 makes this distinction clearer. The results are fairly similar in the two Figures, one exception being the last observation (May 2002) by round, where the cross-sectional poverty is very high due to the crisis, while the panel-based estimates are lower since the impact of the crisis is averaged 
out.

In both Figures, we compare the cross-sectional measures (bold dashed lines) with the risk-adjusted panel-based estimates. With $\rho=0$, the use of the mean normalized adult equivalent income over the four rounds, $\overline{x_{i}}$, reduces poverty compared to the cross-sectional estimates. This is because with zero risk aversion, the "smoothing" effect of averaging income over time leads to lower poverty (transitory income shocks are removed by the averaging), as already pointed out for Figure 2. This "smoothing" effect has been known in the literature of income distribution for a long time. What we point out is that the introduction of risk (and thus considering the disutility from income variation) increases poverty substantially when compared to the estimates obtained using $\rho=0$.

The net impact, i.e. whether the cross-sectional measure is higher or lower than the risk-adjusted and panel-based measure depends on the level of risk aversion assumed. For $\rho=1$, the headcount of risk-adjusted poverty is similar to the cross-sectional headcount. For higher values of $\rho$, however, the impact of risk aversion seems to be larger than the smoothing effect.

What might be a realistic value for $\rho$ ? As noted in Makdissi and Wodon (2003), while Arrow (1971) has argued on theoretical grounds that $\rho$ should be around 1, Friend and Blume (1975) have presented empirical evidence based on portfolio holdings that the coefficient may be around 2, Hildreth and Knowles (1982) have obtained estimates between 1 and 2, and Mehra and Prescott (1985) have used $\rho \in[0,10]$. Cowell and Gardiner (1999) describe different sources and methodologies, as well as a detailed description of the role of risk-aversion in social valuation and its connection with welfare economics. They mention the value of 1.5 which is used by the UK's Treasury for the government's appraisal and evaluation of projects. For poverty measurement, given the difficulty of surviving with very limited income, a value of 2 would not sound unrealistic, in which case cross-sectional estimates would lead to an underestimation of poverty. 


\subsection{Regression analysis}

From a policy perspective, the more interesting results are those obtained from the regression analysis of the determinants of $(\log )$ income and riskadjusted income. The independent variables included in the regressions include (a) household level variables, including the number of babies, children, adults, and elderly household members, and their square, whether the household head has a spouse, whether the household head is a woman, the age of the head and its square, and the migration status of the head (in the last five years); (b) characteristics of the household head, including his/her level of education; whether he/she is unemployed or inactive; whether he/she is an employer, a self-employed worker, or a wage worker; the type of his/her qualification, and whether he/she works in the public sector; and (c) the same set of characteristics for the spouse of the household head, when there is one. All these variables correspond to the initial conditions, that is, the values of the first observation for each household. In addition, we include controls for each of the cohorts (excluding the first one). ${ }^{7}$

Table 3 provides summary statistics of the variables used in the estimation. We estimate the risk-adjusted income regressions only for $\rho=2$, but it would be straightforward to extend the results to higher levels of risk aversion. The sample mean for the logarithm for the average normalized income over time without risk aversion is 0.754 (corresponding to a mean income of 2.13 times the poverty line), while the average logarithm of income with $\rho=2$ is 0.549 (corresponding to a mean income of 1.73 times the poverty line). This suggests that assuming $\rho=2$ as the coefficient for risk aversion results in a drop of income of almost 20 percent. The interpretation of the other variables presented in Table 3 is straightforward (most of the variables are dummies, so that the mean represents the share of the sample population with these characteristics).

\footnotetext{
${ }^{7}$ Note that we do not include in the regressors changes in the right-hand side variables over time, such as changes in unemployment status, because we are not aiming to model the behavioral response of households to shocks at this stage. Such a detailed analysis is beyond the scope of the paper. Here, we limit our analysis to the impact of the initial conditions on risk-adjusted measures of income poverty.
} 
Table 4 presents the results of the regression analysis of the system (9) by SUR in the first two columns, as well as tests for statistically significant differences in the parameter estimates of the two models in the third column (corresponding as explained above to Equation 11). Consider the first column of the table which corresponds to the logarithm of mean income over time without risk aversion $(\rho=0)$. The results are fairly intuitive. A higher household size (whether through more infants, children, or adults) tends to reduce the expected adult equivalent income, but the impact is decreasing at the margin. In the case of elderly members, the impact on income without risk aversion is not statistically significant. However, part of the impact of being elderly may be captured through the inactivity dummies for the household head or spouse, which have a negative impact on mean income. Households with older and/or female heads tend to be richer, though the coefficient on female heads is only significant at the 10 percent level. There seems to be no statistically significant impact from the head being a recent migrant.

Apart from being inactive, being unemployed reduces the expected income for both the head and the spouse, but being an employer or selfemployed worker does not have a statistically significant impact, again for both the head and the spouse (the signs of the coefficients are as expected, given that the excluded category is a wage worker). However, much of the impact of being self-employed may be picked up by the negative and statistically significant coefficient for the informal worker dummy for both the head and the spouse (we use the definition of informality proposed by the International Labor Office for Argentina).

A higher job qualification of the head (at the professional level) or the spouse (at each of the three levels considered) has a positive impact on the expected income of the household, as does the education level of the head and the spouse, with higher levels of education generating progressively higher household income. Being in the public sector reduces expected income in the case of the head (for the spouse, the impact is also negative but not statistically significant). Only the three cohorts corresponding to the period October 1999-May 2002 are associated with statistically significant and neg- 
ative coefficients, reflecting the progressive deepening of the recession. In a nutshell, the data confirm the rather obvious hypothesis that richer households are smaller, better educated, with employed heads or spouses in better quality jobs.

The most interesting results are related to the impact (or lack thereof) of the same independent variables on risk, and thereby on risk-adjusted income. Rather than discussing the parameters obtained in the second column of Table 4, it is easier to directly proceed to the results for the tests of statistically significant differences in the coefficients of the two models, which are presented in column 3. If the difference is found to be not significant, it implies that the dependent variable has the same effect (or lack of effect) in both mean income and risk-adjusted income. However, a significant difference implies that the independent variable has a differential effect on the two dependent variables, or, in other words, it has an effect on risk. As explained in the methodological section, the test of differences in coefficients can also be interpreted as a regression with the risk premium as the dependent variable (Equation 11). In that context, a negative value of the difference represents a negative effect of the variable on the risk premium, while a positive value implies a higher risk premium (and thus a lower utility for the household).

Regarding the structure of the household, only the presence of adults aged 65 and over seems to affect significantly the household's level of risk. The negative difference in column 3 implies that the risk-adjusted adult equivalent income is higher than the straight mean income when the household has elderly members, so that utility is also higher. This can probably be explained by the fact that the elderly often receive a steady stream of income (from pensions or capital assets), and consequently experience less income variability than other age groups, even though their income may be lower, as discussed earlier.

There seems to be no statistically significant impact of the age or gender of the head on risk. Yet other characteristics of the household head do appear to have an impact. First, if the head has migrated to the GBA region (from other provinces in Argentina or from other countries) in the last five 
years, the household appears to suffer more from risk than otherwise. Thus, even if there are no statistically significant differences in mean income between migrants and non-migrants after controlling for human capital, recent migrants may be more exposed to income risk than non-migrants, perhaps because they do have not yet have the possibility of establishing good support networks.

For both the head and the spouse, being unemployed contributes to risk apart from reducing income, as expected. For the head, informality (in the current job, or in the last job if unemployed) also increases risk, and thereby reduces the risk-adjusted income of the household. A higher level of education reduces risk, so that those with little education suffer not only from a lower mean income, but also from a higher income variability. Said differently, investments in human capital seem to pay off not only in terms of returns, but also in terms of lowering the variability of income streams.

Finally, for two cohorts, there is an increase in risk. This is the case for the last cohort, which is not surprising given the fall in real incomes induced by the devaluation of January 2002 (see Figure 2). The other cohort for which there is a higher risk is the cohort for the period covering 1996-1997, during which the impact of the aftermath of the "Tequila crisis", and of the recovery thereafter, may have led to higher income variability.

\section{Conclusion}

In this paper, we have presented a simple and intuitively appealing methodology to incorporate the disutility arising from income variability in the measurement of poverty. The methodology has been applied to household panel data from Argentina for the period 1995-2002. Averaging income data over time at the household level may reduce poverty measures by mitigating the impact of negative shocks, but this effect tends to be more than offset when the disutility from income fluctuations is taken into account. A regression analysis of the determinants of risk-adjusted income reveals that risk is not uniform across households. Households with better educated members 
are not only richer, but also experience lower levels of income variability. Households with recent migrants, as well as households with informal workers and/or unemployed or inactive members tend to suffer more from risk than other types of households. Households with elderly members tend to suffer less from income variability. At the broader macro-economic level, as expected, a crisis tends not only to reduce income levels, but also to increase risk, which magnifies the overall negative impact on poverty. One next step for this analysis could be to relax some of the assumptions made for taking into account the risk aversion of households, for example by testing for the sensitivity of the results to different parameters of risk aversion or to different underlying utility functions.

\section{References}

[1] Arrow, K.J. (1971), Essays in the Theory of Risk-Bearing, HorthHolland, Amsterdam.

[2] Baulch, B. and J. Hoddinott (2000), Economic Mobility and Poverty Dynamics in Developing Countries, Journal of Development Studies, $36(6): 1-24$.

[3] Baulch, B. and N. McCulloch (2000), Simulating the impact of policy upon chronic and transitory poverty in rural Pakistan, Journal of Development Studies, 36(6):100-130.

[4] Blundell, R. and I. Preston (1998), Consumption Inequality and Income Uncertainty, Quarterly Journal of Economics, 113(2): 603-640.

[5] Chaudhuri, S., J. Jalan and A. Suryahadi (2002), Assessing Household Vulnerability to Poverty from Cross-sectional Data: A Methodology and Estimates from Indonesia, Discussion Paper \# 0102-52, Columbia University, Department of Economics, New York.

[6] Christiaensen, L. J. and K. Subbarao (2001), Towards an Understanding of Vulnerability in Rural Kenya. The World Bank. 
[7] Cowell, Frank A. and K. A. Gardiner (2000), Welfare Weights, OFT Economic Research Paper, 202, Office of Fair Trading, London.

[8] Cruces, G. and Q. Wodon (2003a), Argentina's Crises and the Poor, 1995-2002, STICERD-DARP Working Paper 71, London, UK.

[9] Cruces, G. and Q. Wodon (2003b), Transient and Chronic Poverty in Turbulent Times: Argentina 1995-2002, mimeo, STICERD and World Bank.

[10] Cruces, G., P. Makdissi and Q. Wodon (2002), Risk aversion and long term deprivation: An application to poverty in the United Kingdom, mimeo, World Bank.

[11] Dabalen, A. and N. Poupart (2002), Vulnerability to Rainfall Shock in Ethiopia, Paper presented at the IFPRI-World Bank Conference on Risk and Vulnerability: Estimation and Policy Implications, Washington, D.C., September 23-24, 2002.

[12] Dercon, S. and P. Krishnan (2000), Vulnerability, Seasonality and Poverty in Ethiopia, Journal of Development Studies, 36(6):25-53.

[13] Foster, J., J. Greer, and E. Thorbecke (1984), A class of decomposable poverty measures, Econometrica, 52:761-65

[14] Friend, I. and M.E. Blume (1975), The Demand for Risky Assets, American Economic Review, 65:900-922.

[15] Gunning, J.W., J. Hoddinott, B. Kinsey and T. Owens (2000), Revisiting forever gained: income dynamics in the resettlement areas of Zimbabwe, 1983-96, Journal of Development Studies, 36(6):132-154.

[16] Hildreth, C. and G.J. Knowles (1982), Some Estimates of Farmers Utility Functions, Technical Bulletin 335, Agricultural Experimental Station, University of Minnesota. 
[17] INDEC (2002), Incidencia de la Pobreza y de la indigencia en los aglomerados urbanos - Mayo 2002, Informacion de Prensa, ISSN 0327-7968, Buenos Aires.

[18] Jalan, J. and M. Ravallion (1999), Are the Poor Less Well Insured? Evidence on Vulnerability to Income Risk in Rural China, Journal of Development Economics, 58:61-81.

[19] Jalan, J. and M. Ravallion (2000), Is Transient Poverty Different? Evidence for Rural China, Journal of Development Studies, 36(6): 82-99.

[20] Ligon, E. and L. Schechter (2002), Measuring vulnerability, Paper presented at the IFPRI-World Bank Conference on Risk and Vulnerability: Estimation and Policy Implications, Washington, D.C., September 23$24,2002$.

[21] Makdissi, P. and Q. Wodon (2003), Risk-adjusted measures of wage inequality and safety nets, Economics Bulletin, Vol. 9, No. 1 pp. 1-10.

[22] Mansuri, G. and A. Healy (2002), Vulnerability Prediction in Rural Pakistan, Paper presented at the IFPRI-World Bank Conference on Risk and Vulnerability: Estimation and Policy Implications, Washington, D.C., September 23-24, 2002.

[23] Mehra, R. and E.C. Prescott (1985), The Equity Premium, Journal of Monetary Economics, 15:145-161.

[24] Morales, E. (1988), Canasta básica de alimentos - Gran Buenos Aires, Documento de trabajo ${ }^{o}$ 3. INDEC / IPA, Buenos Aires.

[25] Ravallion, M. (1988), Expected Poverty under Risk-induced Welfare Variability, Economic Journal, 98:1171-1182.

[26] Scott, C. (2000), Mixed fortunes: a study of poverty mobility among small farm households in Chile, 1968-1986, Journal of Development Studies, 36(6):155-180. 
[27] Skoufias, E. and A. Quisumbing (2002), Consumption Insurance and Vulnerability to Poverty: A Synthesis of the Evidence from Bangladesh, Ethiopia, Mali, Mexico and Russia, Paper presented at the IFPRI-World Bank Conference on Risk and Vulnerability: Estimation and Policy Implications, Washington, D.C., September 23-24, 2002.

[28] World Bank (2000), Argentina: Poor People in a Rich Country, Report No. 19992-AR, Washington, DC.

[29] World Bank (2001a), World Development Report 2000-2001: Attacking Poverty, Oxford University Press, Oxford.

[30] World Bank (2001b), Household Risk, Self-Insurance and Coping Strategies in Urban Argentina, Report No. 22426-AR, Washington DC. 
Table 1: Sample size in cross-section and panel data sets

\begin{tabular}{|c|cc|c|cc|}
\hline Wave & $\begin{array}{c}\text { Original } \\
\text { Sample }\end{array}$ & $\begin{array}{c}\text { Final } \\
\text { Sample }\end{array}$ & Cohort & $\begin{array}{c}\text { Number of } \\
\text { Observatoins }\end{array}$ & $\begin{array}{c}\text { Number of } \\
\text { Households }\end{array}$ \\
\hline May 95 & 3463 & 418 & $\mathbf{9 5 - 1 / 9 6 - 2}$ & 1672 & 418 \\
Oct. 95 & 3436 & 879 & $\mathbf{9 5 - 2 / 9 7 - 1}$ & 1844 & 461 \\
May 96 & 3459 & 1322 & $\mathbf{9 6 - 1 / 9 7 - 2}$ & 1772 & 443 \\
Oct. 96 & 3369 & 1774 & $\mathbf{9 6 - 2 / 9 8 - 1}$ & 1808 & 452 \\
May 97 & 3424 & 1815 & $\mathbf{9 7 - 1 / 9 8 - 2}$ & 1832 & 458 \\
Oct. 97 & 3423 & 1843 & $\mathbf{9 7 - 2 / 9 9 - 1}$ & 1960 & 490 \\
May 98 & 3549 & 1899 & $\mathbf{9 8 - 1 / 9 9 - 2}$ & 1992 & 498 \\
Oct. 98 & 3567 & 1923 & $\mathbf{9 8 - 2 / 0 1 - 1}$ & 1904 & 476 \\
May 99 & 3551 & 1938 & $\mathbf{9 9 - 1 / 0 0 - 2}$ & 1892 & 473 \\
Oct. 99 & 3494 & 1870 & $\mathbf{9 9 - 2 / 0 1 - 1}$ & 1692 & 423 \\
May 00 & 3528 & 1822 & $\mathbf{0 0 - 1 / 0 1 - 2}$ & 1800 & 450 \\
Oct. 00 & 3521 & 1750 & $\mathbf{0 0 - 2 / 0 2 - 1}$ & 1616 & 404 \\
May 01 & 3473 & 1277 & \multicolumn{3}{|}{} \\
Oct. 01 & 3453 & 854 & \multicolumn{3}{|l}{} \\
May 02 & 3505 & 404 & & & \\
\hline
\end{tabular}

Source: Authors' estimation based on EPH, various years.

Table 2: Two ways of looking at the panel data: Cohorts and waves

\begin{tabular}{|c|c|c|c|c|c|c|c|c|c|c|c|c|c|c|c|c|}
\hline & Wave: & $95-1$ & $95-2$ & $96-1$ & $96-2$ & $97-1$ & $97-2$ & 98-1 & $98-2$ & $99-1$ & $99-2$ & $00-1$ & $00-2$ & 01-1 & $01-2$ & $02-1$ \\
\hline & Cohort: & & & & & & & & & & & & & & & \\
\hline 1 & $95-1$ to $96-2$ & 1 & 1 & 1 & 1 & & & & & & & & & & & \\
\hline 2 & $95-2$ to $97-1$ & & 2 & 2 & 2 & 2 & A & & & & & & & & & \\
\hline 3 & $96-1$ to $97-2$ & & & 3 & 3 & 3 & 3 & & & & & & & & & \\
\hline 4 & $96-2$ to $98-1$ & & & & 4 & 4 & 4 & 4 & & & & & & & & \\
\hline 5 & $97-1$ to $98-2$ & & & & & 5 & 5 & 5 & 5 & & & & & & & \\
\hline 6 & $97-2$ to $99-1$ & & & & & & 6 & 6 & 6 & 6 & & & & & & \\
\hline 7 & $98-1$ to $99-2$ & & & & & & & 7 & 7 & 7 & 7 & & & & & \\
\hline 8 & $98-2$ to $01-1$ & & & & & & & & 8 & 8 & 8 & 8 & $\rightarrow$ & Cohort & & \\
\hline 9 & $99-1$ to $00-2$ & & & & & & $\downarrow$ & & & 9 & 9 & 9 & 9 & & & \\
\hline 10 & $99-2$ to $01-1$ & & & & & & Wave & & & & 10 & 10 & 10 & 10 & & \\
\hline 11 & $00-1$ to $01-2$ & & & & & & & & & & & 11 & 11 & 11 & 11 & \\
\hline 12 & $00-2$ to $02-1$ & & & & & & & & & & & & 12 & 12 & 12 & 12 \\
\hline
\end{tabular}

Source: Authors' estimation based on EPH, various years. 
Table 3: Summary statistics for the dependent and independent variables

\begin{tabular}{|c|c|c|c|c|}
\hline Variable & Mean & Std. Dev. & Min & Max \\
\hline Log of Risk Adjusted Income, $\rho=2$ & 0.549 & 1.129 & -4.61 & 3.933 \\
\hline Log of Average Income & 0.754 & 0.844 & -4.61 & 3.951 \\
\hline Number of infants $0-5$ & 0.349 & 0.693 & 0 & 6 \\
\hline Number of children 6-14 & 0.543 & 0.922 & 0 & 8 \\
\hline Number of youth 15-24 & 0.586 & 0.907 & 0 & 6 \\
\hline Number of adults $25-64$ & 1.552 & 0.940 & 0 & 6 \\
\hline Number of elderly $65+$ & 0.395 & 0.677 & 0 & 4 \\
\hline Age of the head & 51.002 & 16.061 & 15 & 96 \\
\hline Share of female headed households & 0.242 & 0.428 & 0 & 1 \\
\hline Head is recent migrant & 0.026 & 0.159 & 0 & 1 \\
\hline Head inactive & 0.279 & 0.449 & 0 & 1 \\
\hline Head unemployed & 0.069 & 0.254 & 0 & 1 \\
\hline Head as employer & 0.032 & 0.177 & 0 & 1 \\
\hline Head as self-employed & 0.143 & 0.351 & 0 & 1 \\
\hline Head as informal worker & 0.232 & 0.422 & 0 & 1 \\
\hline Head in public sector & 0.082 & 0.274 & 0 & 1 \\
\hline Head as operative (qualification) & 0.350 & 0.477 & 0 & 1 \\
\hline Head as technical worker (qualification) & 0.112 & 0.315 & 0 & 1 \\
\hline Head as professional worker (qualification) & 0.068 & 0.252 & 0 & 1 \\
\hline Head with primary education - Complete & 0.345 & 0.475 & 0 & 1 \\
\hline Head with secondary education - Incomplete & 0.177 & 0.382 & 0 & 1 \\
\hline Head with secondary education - Complete & 0.143 & 0.350 & 0 & 1 \\
\hline Head with superior education - Incomplete & 0.008 & 0.090 & 0 & 1 \\
\hline Head with superior education - Complete & 0.026 & 0.158 & 0 & 1 \\
\hline Head with university education & 0.146 & 0.353 & 0 & 1 \\
\hline No spouse in the household & 0.306 & 0.461 & 0 & 1 \\
\hline Spouse inactive & 0.418 & 0.493 & 0 & 1 \\
\hline Spouse unemployed & 0.048 & 0.215 & 0 & 1 \\
\hline Spouse as employer & 0.007 & 0.081 & 0 & 1 \\
\hline Spouse as self-employed & 0.056 & 0.229 & 0 & 1 \\
\hline Spouse as informal worker & 0.103 & 0.303 & 0 & 1 \\
\hline Spouse as operative (qualification) & 0.066 & 0.249 & 0 & 1 \\
\hline Spouse as technical worker (qualification) & 0.050 & 0.218 & 0 & 1 \\
\hline Spouse as professional worker (qualification) & 0.026 & 0.159 & 0 & 1 \\
\hline Spouse in public sector & 0.044 & 0.206 & 0 & 1 \\
\hline Spouse with primary education - Complete & 0.252 & 0.434 & 0 & 1 \\
\hline Spouse with secondary education - Incomplete & 0.115 & 0.319 & 0 & 1 \\
\hline Spouse with secondary education - Complete & 0.119 & 0.324 & 0 & 1 \\
\hline Spouse with superior education - Incomplete & 0.010 & 0.097 & 0 & 1 \\
\hline Spouse with superior education - Complete & 0.034 & 0.182 & 0 & 1 \\
\hline Spouse with university education & 0.071 & 0.257 & 0 & 1 \\
\hline
\end{tabular}




\begin{tabular}{|c|c|c|c|}
\hline & Income [2] & $\begin{array}{c}\text { Risk-adjusted } \\
\text { income [1] }\end{array}$ & $\begin{array}{c}\text { Difference [2]-[1] } \\
\text { and P-value }\end{array}$ \\
\hline \multicolumn{4}{|c|}{ HOUSEHOLD CHARACTERISTICS } \\
\hline \multirow[t]{2}{*}{ Number of infants $0-5$} & -0.272 & -0.297 & 0.024 \\
\hline & {$[0.02661]^{* * *}$} & {$[0.04225]^{* * *}$} & 0.378 \\
\hline \multirow[t]{2}{*}{ Infants squared } & 0.028 & 0.030 & -0.002 \\
\hline & {$[0.01007]^{* * *}$} & {$[0.01600]^{*}$} & 0.819 \\
\hline \multirow[t]{2}{*}{ Number of children $6-14$} & -0.374 & -0.365 & -0.009 \\
\hline & {$[0.01826]^{* * *}$} & {$[0.02899] * * *$} & 0.640 \\
\hline \multirow[t]{2}{*}{ Children squared } & 0.040 & 0.034 & 0.006 \\
\hline & {$[0.00539]^{* * *}$} & {$[0.00855]^{* * *}$} & 0.258 \\
\hline \multirow[t]{2}{*}{ Number of youth $15-24$} & -0.209 & -0.187 & -0.023 \\
\hline & {$[0.01913]^{* * *}$} & {$[0.03038]^{* * *}$} & 0.251 \\
\hline \multirow[t]{2}{*}{ Youth squared } & 0.038 & 0.042 & -0.004 \\
\hline & {$[0.00630]^{* * *}$} & {$[0.01000]^{* * *}$} & 0.521 \\
\hline \multirow[t]{2}{*}{ Number of adults $25-64$} & -0.096 & -0.085 & -0.011 \\
\hline & {$[0.02706]^{* * *}$} & {$[0.04295]^{* *}$} & 0.695 \\
\hline \multirow[t]{2}{*}{ Adults squared } & 0.023 & 0.027 & -0.004 \\
\hline & {$[0.00642]^{* * *}$} & {$[0.01019]^{* * *}$} & 0.559 \\
\hline \multirow[t]{2}{*}{ Number of elderly $65+$} & 0.016 & 0.115 & -0.099 \\
\hline & {$[0.03901]$} & {$[0.06194]^{*}$} & $0.014 * *$ \\
\hline \multirow[t]{2}{*}{ Elderly squared } & -0.021 & -0.039 & 0.018 \\
\hline & {$[0.01667]$} & {$[0.02646]$} & 0.293 \\
\hline \multicolumn{4}{|c|}{ CHARACTERISTICS OF THE HEAD } \\
\hline \multirow[t]{2}{*}{ Age } & 0.007 & 0.009 & -0.002 \\
\hline & {$[0.00355]^{* *}$} & {$[0.00563]^{*}$} & 0.570 \\
\hline \multirow[t]{2}{*}{ Age Squared } & 0.000 & 0.000 & 0.000 \\
\hline & {$[0.00004]$} & {$[0.00006]$} & 0.998 \\
\hline \multirow[t]{2}{*}{ Female head } & 0.051 & 0.079 & -0.028 \\
\hline & {$[0.02658]^{*}$} & {$[0.04219]^{*}$} & 0.312 \\
\hline \multirow[t]{2}{*}{ Recent migrant } & -0.010 & -0.098 & 0.089 \\
\hline & {$[0.04660]$} & {$[0.07398]$} & 0.065 \\
\hline \multirow[t]{2}{*}{ Inactive } & -0.134 & -0.157 & 0.022 \\
\hline & {$[0.04082]^{* * *}$} & {$[0.05242] * * *$} & 0.512 \\
\hline \multirow[t]{2}{*}{ Unemployed } & -0.440 & -0.866 & 0.426 \\
\hline & {$[0.05073]^{* * *}$} & {$[0.05790]^{* * *}$} & $0.000 * * *$ \\
\hline \multirow[t]{2}{*}{ Employer } & 0.071 & 0.020 & 0.051 \\
\hline & [0.04619] & {$[0.07333]$} & 0.287 \\
\hline \multirow[t]{2}{*}{ Self-employed } & -0.051 & 0.047 & -0.098 \\
\hline & {$[0.02762]$} & {$[0.04386]$} & 0.401 \\
\hline \multirow[t]{2}{*}{ Informal Worker } & -0.147 & -0.224 & 0.077 \\
\hline & {$[0.02540]^{* * *}$} & {$[0.04032]^{* * *}$} & $0.003 * * *$ \\
\hline \multirow[t]{2}{*}{ Public Sector Worker } & -0.063 & -0.035 & -0.028 \\
\hline & {$[0.02927]^{* *}$} & {$[0.04646]$} & 0.350 \\
\hline \multirow[t]{2}{*}{ Job Qualification: Operative } & 0.121 & 0.158 & -0.037 \\
\hline & {$[0.03997]$} & {$[0.03914] * * *$} & 0.143 \\
\hline Job Qualification: Technical & 0.336 & 0.372 & -0.036 \\
\hline & {$[0.05132]$} & {$[0.05480]^{* * *}$} & 0.315 \\
\hline Job Qualification: Professional & 0.244 & 0.698 & -0.454 \\
\hline & {$[0.04329]^{* * *}$} & {$[0.06873]^{* * *}$} & 0.424 \\
\hline
\end{tabular}


Table 4 (continued): Determinants of log adult equivalent income and log risk-adjusted income

Primary education - Complete

Secondary education - Incomplete

Secondary education - Complete

Superior education - Incomplete

Superior education - Complete

University education

No Spouse

CHARACTERISTICS OF THE HEAD'S SPOUSE

Inactive

Unemployed

Employer

Self-employed

Informal Worker

Job Qualification: Operative

Job Qualification: Technical

Job Qualification: Professional

Public Sector Worker

Primary education - Complete

Secondary education - Incomplete

Secondary education - Complete

Superior education - Incomplete

Superior education - Complete

University education
0.156
$[0.02288]^{* * *}$
0.319
$[0.02705]^{* * *}$
0.534
$[0.03460]^{* * *}$
0.217
$[0.08275]^{* * *}$
0.731
$[0.05243]^{* * *}$
0.423
[0.04477]***
0.103
$[0.05138]^{* *}$

-0.244
$[0.03302]^{* * *}$
-0.355
$[0.03647]^{* * *}$
-0.044
$[0.09697]$

0.024

[0.04175]

$-0.097$

[0.04289]**

0.052

$[0.02465]^{* * *}$

0.075

$[0.03452]^{* * *}$

0.662

$[0.06642]^{* * *}$

$-0.017$

[0.04416]

0.152

[0.02857]***

0.229

$[0.03370]^{* * *}$

0.313

[0.02942]***

0.754

$[0.07953]^{* * *}$

0.371

$[0.05219]^{* * *}$

0.777

$[0.03400]^{* * *}$
0.196

$[0.03632]^{* * *}$

0.345

[0.04294]***

0.604

$[0.04670]^{* * *}$

0.976

$[0.13137]^{* * *}$

0.833

$[0.08285]^{* * *}$

0.847

$[0.05398]^{* * *}$

0.059

[0.08157]

$-0.331$

$[0.06480]^{* * *}$

$-0.543$

[0.08053]***

$-0.126$

[0.15395]

$-0.071$

[0.06629]

$-0.122$

[0.06810]*

0.024

[0.06347]

0.090

[0.08147]

0.244

$[0.10545]^{* *}$

$-0.027$

[0.07011]

0.207

$[0.04535]^{* * *}$

0.306

$[0.05351]^{* * *}$

0.425

$[0.05492]^{* * *}$

0.177

[0.12627]

0.477

$[0.08323]^{* * *}$

0.517

$[0.07107]^{* * *}$
$-0.039$

$0.096 *$

$-0.027$

0.341

$-0.070$

$0.021 * *$

$-0.759$

$0.009 * * *$

$-0.103$

$0.056 *$

$-0.423$

$0.049 * *$

0.044

0.402

0.087

$0.040 * *$

0.187

$0.000 * * *$

0.082

0.413

0.095

0.636

0.025

0.568

0.028

0.496

$-0.015$

0.770

0.418

0.996

0.011

0.816

$-0.056$

$0.060 *$

$-0.076$

$0.028 * *$

$-0.112$

$0.002 * * *$

0.578

0.625

$-0.106$

$0.051 *$

0.260

$0.042 * *$ 
Table 4 (continued): Determinants of log adult equivalent income and log risk-adjusted income COHORT CONTROLS

95-2/97-1

$96-1 / 97-2$

$96-2 / 98-1$

$97-1 / 98-2$

$97-2 / 99-1$

98-1/99-2

98-2/01-1

$99-1 / 00-2$

99-2/01-1

$00-1 / 01-2$

$00-2 / 02-1$

Constant
$-0.038$

[0.03653]

$-0.013$

[0.03672]

$-0.003$

[0.03615]

0.034

[0.03606]

0.021

[0.03559]

$-0.043$

[0.03549]

$-0.028$

[0.03579]

$-0.022$

[0.03575]

$-0.107$

$[0.03670]^{* * *}$

$-0.115$

$[0.03635]^{* * *}$

$-0.164$

$[0.03723]^{* * *}$

0.424

$[0.09885]^{* * *}$

Observations

5446

$-0.083$

0.046

[0.05800]

0.226

$-0.084$

0.071

[0.05829]

0.062

$-0.042$

0.039

[0.05739]

0.297

0.008

0.025

[0.05725]

0.494

0.026

$-0.004$

[0.05651]

0.904

$-0.070$

0.027

[0.05634]

0.459

$-0.037$

0.010

[0.05682]

0.797

$-0.031$

0.008

[0.05675]

0.819

$-0.108$

0.001

[0.05826]*

0.975

$-0.127$

0.012

$[0.05770]^{* *}$

0.748

$-0.316$

0.152

$[0.05911]^{* * *}$

$0.000 * * *$

Standard errors in brackets (significant: * at 10\%; ** at 5\%; *** at $1 \%$ )

0.080 $[0.15693]$

(P-Value of the test below the difference for the fourth column)

Source: Authors' estimation based on EPH, various years. 
Figure 1 - Complete Sample and Panel Sub-Sample

GBA 1995-2002

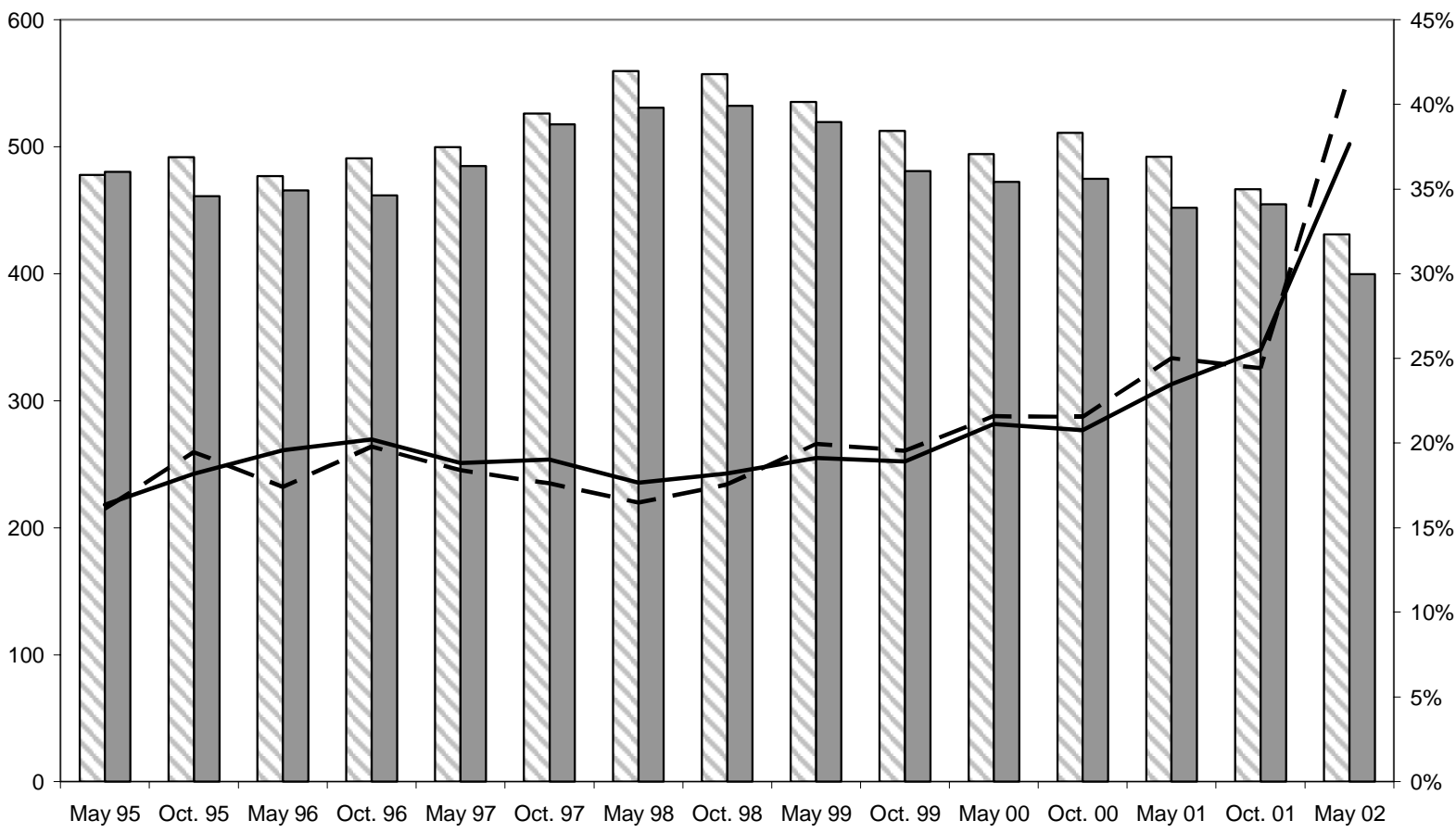

$\square$ Nom. Income - All $\square$ Nom. Income - Sample —Poverty - All — - Poverty-Sample

Figure 2 - Risk Adjusted Normalised Income

GBA, 1995-2002

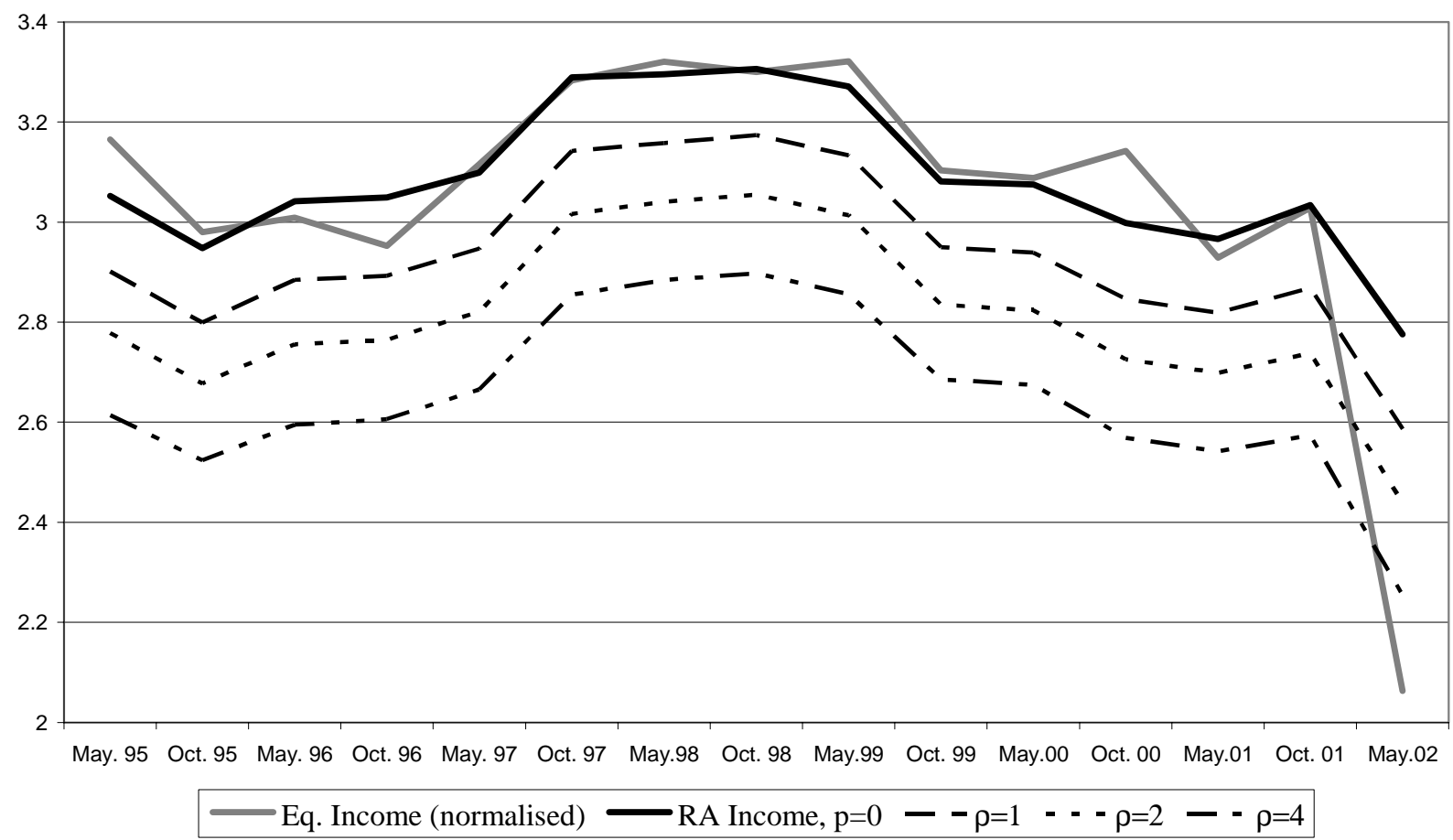


Figure 3 - Risk Adjusted Measures of Poverty by Wave

GBA 1995-2002

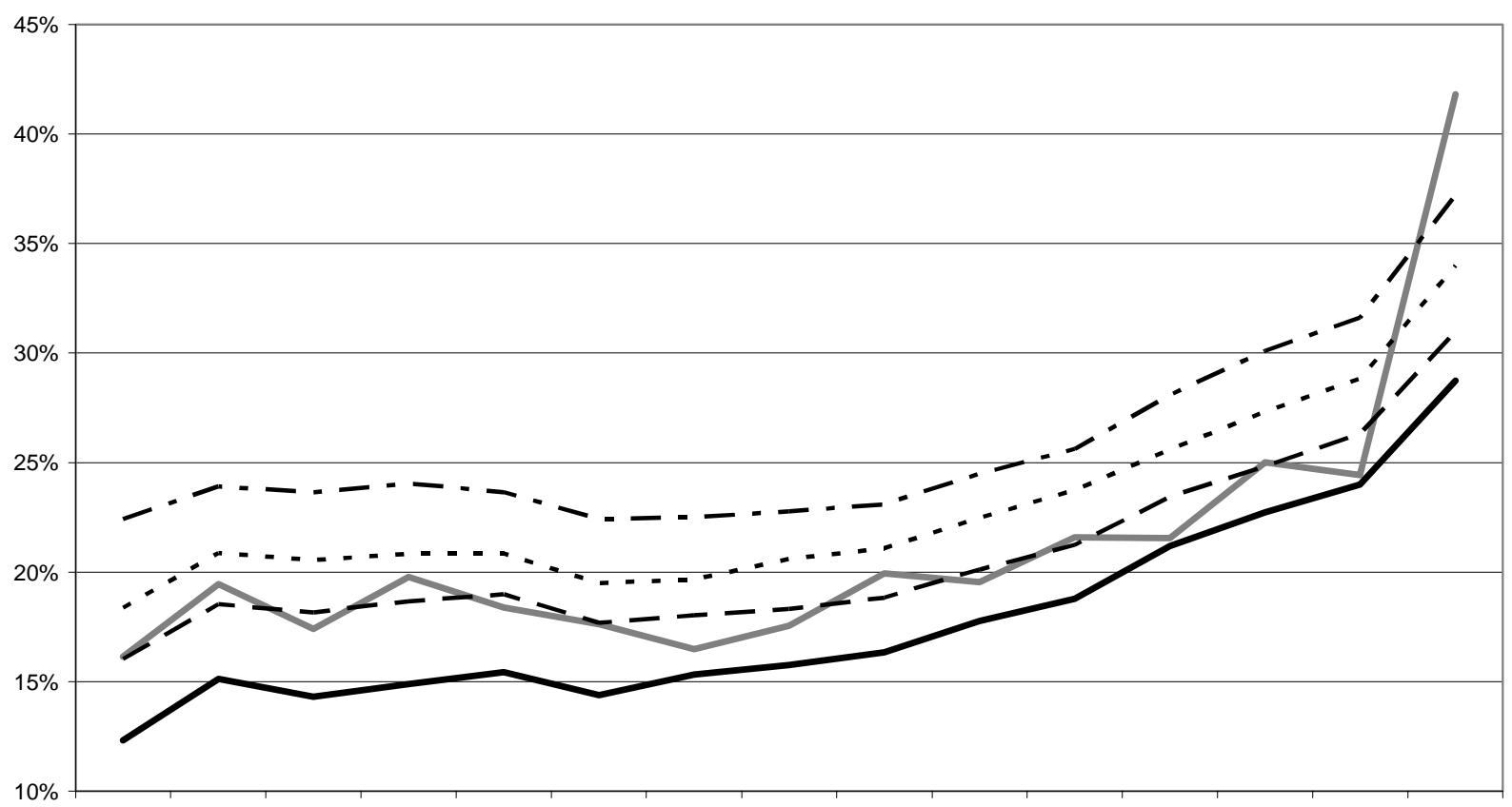

May. 95 Oct. 95 May. 96 Oct. 96 May. 97 Oct. 97 May.98 Oct. 98 May.99 Oct. 99 May.00 Oct. 00 May.01 Oct. 01 May.02 $\longrightarrow$ Poor (Sample) $\longrightarrow \rho=0--\rho=1--\rho=2-\rho=4$

Figure 4 - Risk Adjusted Measures of Poverty by Cohorts GBA, 1995-2002

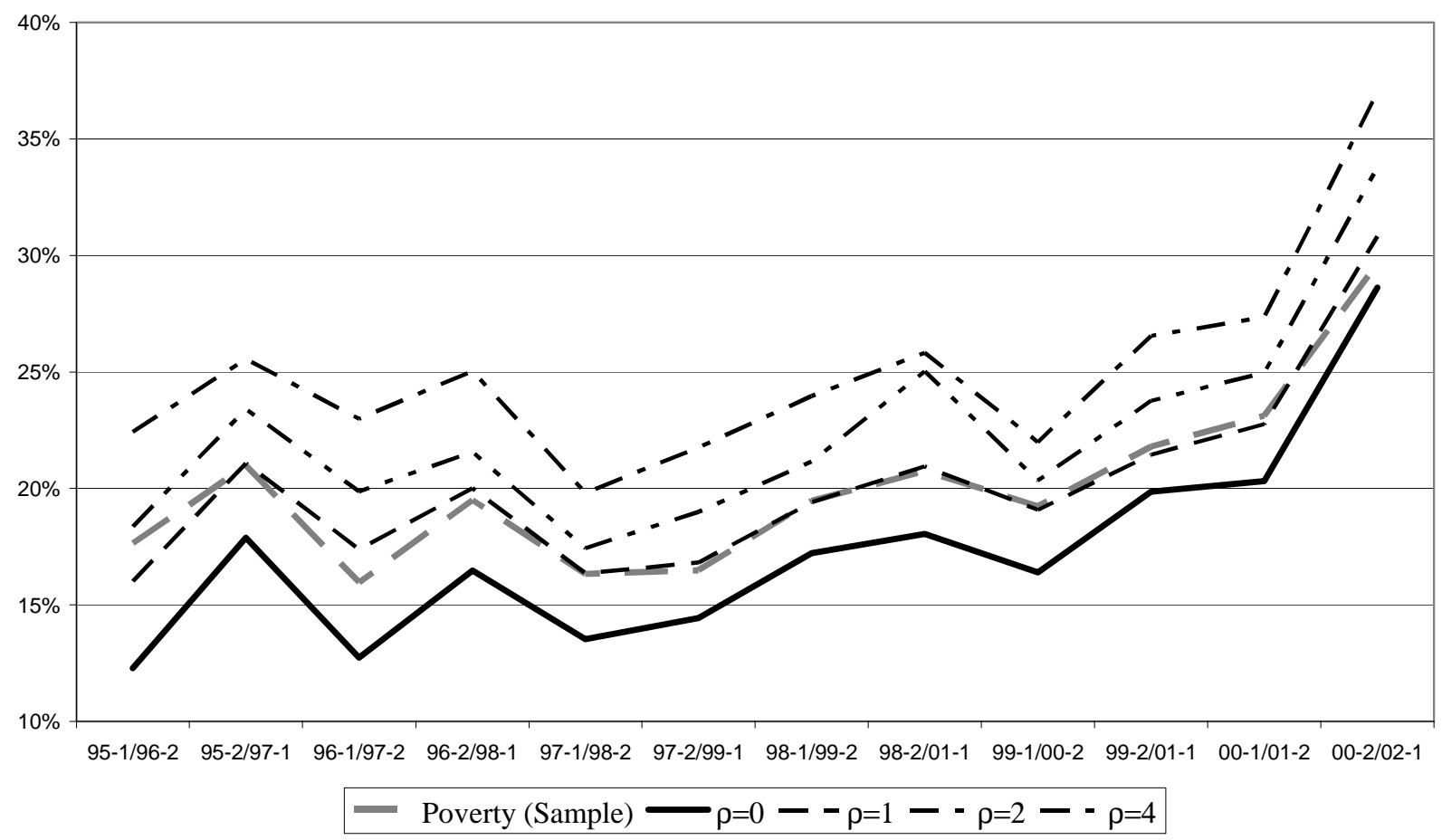

